\title{
The Pascal's Law of Physics Applied to Build a Reuse Material Robotic as Effective Physics Leaning Media
}

Korn Taksapattanakul*, Arom Puteh, Ahamad Arun, Suchada Saengwiman

Faculty of Science and Technology, Princess of Naradhiwas University, Naradhiwas, 96000, Thailand

\section{ARTICLE INFO}

\section{Article history:}

Received: 28 Dec 2019

Revised: 04 March 2020

Accepted: 05 March 2020

Published online: 24 April 2020

\section{Keywords:}

Pascal's law

Reuse material robotic

Physics leaning media

Hydraulic system

\begin{abstract}
A B S T R A C T
The Pascal's law is a part of physics subject which difficult for students to imagine and understand. Therefore, the aim of this work is to help the students to easily understand the Pascal's law via studying the effect of fluid volume on movement joint mechanisms degree and applying to build a reuse material robotic as effective physics leaning media. The process start with teaching the students about the Pascal's law. After that, encouraged the students to test the effect of fluid volume to each joint movement. Finally, they can assemble each component to build a movement robot. It was found that the students can understand the Pascal's law after studied and analyzed the effect of fluid volume on join movement of each part of the robot. This knowledge helped student to build a robot that can successfully move by the Pascal's law. Thus, this leaning media is an important development leaning skill of students about the Pascal's law in physics.
\end{abstract}

\section{Introduction}

In modern education, learning media is very important. It can help students understand the content of the study and learning skills including create interest in the subject. In many science subjects, it is necessary to have learning media to gain students interest, such as Pascal's law topics in physics. Therefore, we create one of the tools to help students who do not understand the content of Pascal's law by using learning media to help explain along with the content.

Pascal's law topic in physics is the most fundamental principle in fluid power (Johnson, 2002) and it can be applied to build hydraulic systems. Hydraulic systems can be divided into three main parts: (1) power supply, (2) control, and (3) output. The power supply part supplies flow to the systems. It takes the mechanical power from the actuator and converts it to fluid power. The output part of the system includes the actuator and the load. The actuator converts the

${ }^{*}$ Corresponding author. Tel./Fax.: +66918472196

E-mail: korn.t@pnu.ac.th 
fluid power back into mechanical power, which is used to move the load. The control part includes directional control valves, pressure control valves, and flow control valves (Johnson, 2002). For the students to more understand the teaching and learning of Pascal's law, there must be examples of technologies that use Pascal's law. Due to the modern technology that uses Pascal's law as a basic and combined with other technologies, resulting to students does not understand the basic principle of Pascal's law. Most of inventions that uses Pascal's law are combined with other technologies such as robot by using generic algorithm and computer-based (Bahaa et al., 2008; Anisur et al., 2013; Surendernath et al., 2015; Jônatas et al., 2015; Redmond et al., 2018; Kurt et al., 2010; Bin et al., 2017; Ross et al., 2017; Ashraf et al., 2011; Alka et al., 2017) the mechanical and hydraulic systems (Jiaqi et al., 2016; Abhinav et al., 2019; Hitoshi et al., 2012; Stevenson et al., 1986). Although, the hydraulic-powered robotic arm (Faiyaz et al., 2018) was studied but it is still not explaining of the Pascal's law in the system. From the research that mention earlier, no research studied the effect of fluid volume on movement joint mechanisms degree along with explain the basic principle of Pascal's law via build the robotic learning media.

Therefore, this work was explained and demonstrated the Pascal's law of physics to build a reuse material robotic as effective physics leaning media and the hydraulic systems were studied for the effect of fluid volume on movement mechanisms degree of robotic learning media. The students can understand the Pascal's law and participate in activities to create robotic leaning media by themselves.

\section{Methodology}

\section{Materials}

The main parts were built using reuse material as shown in Table 1

Table 1 . The reuse main materials

\begin{tabular}{ccccc}
\hline Segment & Types & Dimension (cm) & $\begin{array}{c}\text { Number of } \\
\text { pieces }\end{array}$ & Shape \\
\hline \multirow{6}{*}{ Robotic arm } & Plastic-board & $3.5 \times 25$ & 4 & Rectangle \\
& Plastic-board & $3.5 \times 27.5$ & 4 & Rectangle \\
& Plastic-board & $20 \times 26$ & 2 & Rectangle \\
& Plastic-board & $5 \times 6.5$ & 2 & Rectangle \\
& Plastic-board & $2 \times 8$ & 4 & Rectangle \\
& Plastic-board & $2 \times 7$ & 4 & Rectangle \\
& Plastic-board & $10 \times 10$ & 2 & Square \\
& Plastic-board & $5.5 \times 15.5 \times 15.5 \times 10$ & 4 & Trapezoid \\
& Plastic-board & $5.5 \times 13 \times 5.5$ & 2 & Triangle \\
& Plastic-board & $11 \times 13$ & 2 & Rectangle \\
Robotic leg & Plastic-board & $10 \times 13$ & 2 & Rectangle \\
& Plastic-board & $5 \times 10$ & 4 & Rectangle \\
& Plastic-board & $5 \times 12$ & 4 & Rectangle \\
& Plastic-board & $5 \times 30$ & 4 & Rectangle \\
Robotic body & Plastic-board & $7 \times 29$ & 4 & Rectangle \\
& Plastic-board & $25.5 \times 30$ & 4 & Rectangle \\
\hline
\end{tabular}




\begin{tabular}{ccccc}
\hline & & & & \\
\hline \multirow{2}{*}{ Robotic head } & Plastic-board & $26 \times 30$ & 2 & Rectangle \\
Plastic-board & $18 \times 21$ & 6 & Rectangle \\
10 and $20 \mathrm{ml}$ & syringes & 14 & - \\
& $\begin{array}{c}\text { Rubber tubes } \\
\text { for syringes } \\
\text { Small pieces of } \\
\text { bamboo wood } \\
\text { Small tubes }\end{array}$ & - & 14 & - \\
\hline & & - & a lots & - \\
& & & 2 & $\begin{array}{c}\text { Circular } \\
\text { cylinder }\end{array}$ \\
\hline
\end{tabular}

\section{The building model of robotic learning media}

The high-school students studied the basic of Pascal's law in class after that they used this knowledge applied to build a robotic learning media together with study the effect of fluid volume on movement joint mechanisms degree.

\section{Robotic arm segments (left and right)}

On the base, the two pieces of plastic-board are glued and drilled in the middle of plastic-board. The small tubes are used to fix at the drilled part of the arm with the base for rotation.

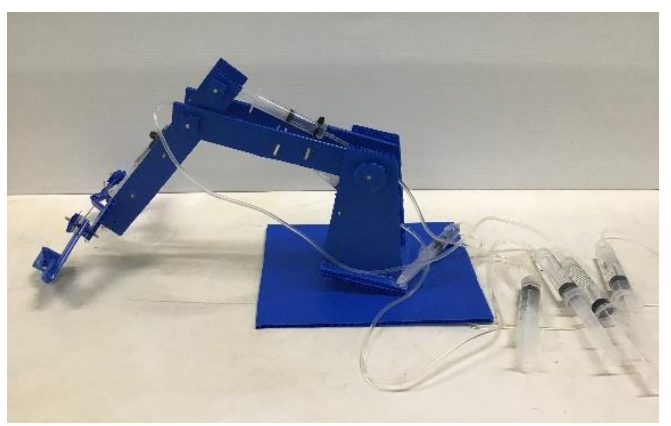

Figure 1. Robotic arm segments

The arm build using pieces of plastic-board, glue, a triangle piece of plastic-board, short wires, small pieces of bamboo wood and syringes with rubber tubes are used to control and fixed as shown in figure 1.

\section{Robotic leg segments (left and right)}

The leg build using pieces of plastic-board, glue, small pieces of bamboo wood and syringes with rubber tubes are used to control and fixed as shown in figure 2. 


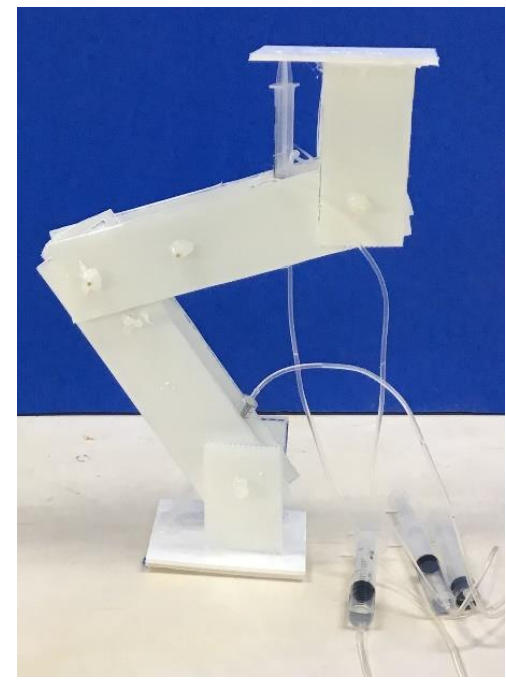

Figure 2. Robotic leg segments

\section{Robotic head and body segments}

The head and body build using pieces of plastic-board and glue.

Robotic learning media is assembled using arm segments, leg segments, body segment, head segment and glue as presented in figure 3 .
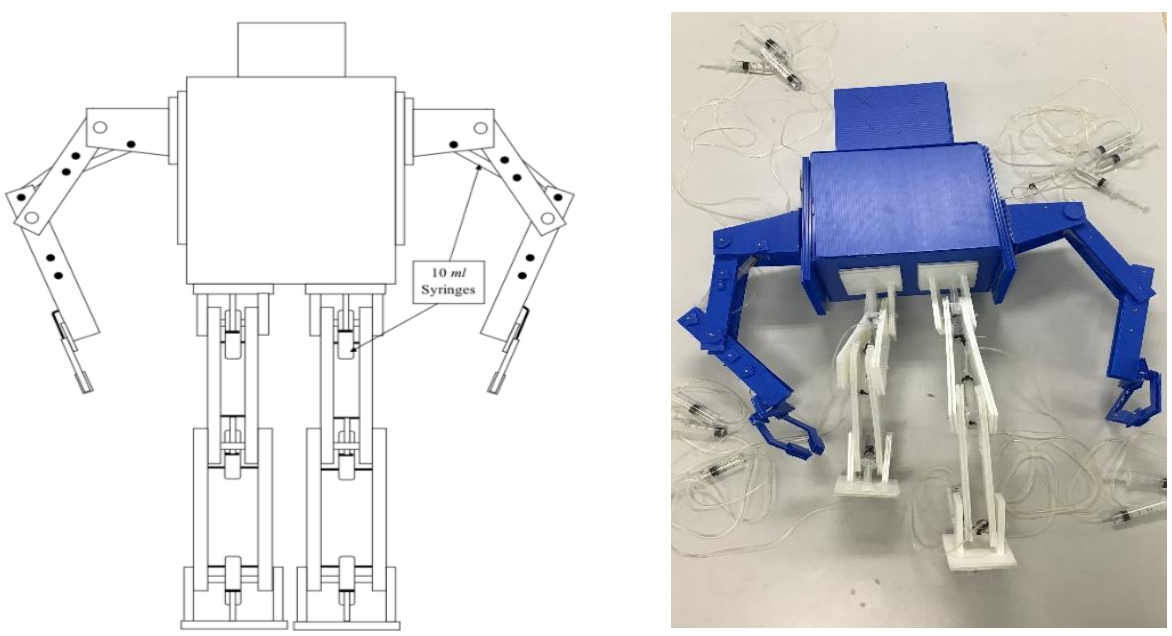

Figure 3. Model of robotic learning media

The Pascal's law of physics applied to build hydraulic systems of robotic leaning media

Pascal's law is the principle in fluid power. In this work, the fluid power was presented in term of water syringe (hydraulic systems). The effect of fluid volume in hydraulic systems on movement mechanisms degree of robotic learning media was studied with Pascal's law (Johnson, 2002). The students tested the effect of fluid volume to each joint movement as follow: the pressing (decrease fluid volume) on $20 \mathrm{ml}$ syringes as control and related to $10 \mathrm{ml}$ syringes as fixed at the 
joints (increase fluid volume) and the pulling (increase fluid volume) on $20 \mathrm{ml}$ syringes and related to $10 \mathrm{ml}$ syringes (decrease fluid volume), it created a force to move one of the movement mechanisms degree of robotic learning media. The increase fluid volume, decrease fluid volume and degree of movement mechanisms were tested and recorded. Finally, we encouraged students to assemble each component to build a movement robot by themselves.

\section{Results and Discussion}

The Pascal's law of physics was applied to build a reuse material robotic leaning media and the water syringes as hydraulic system was studied the pressing and pulling process effect of fluid volume on movement mechanisms degree of joint robotic model. The Pascal's law (Johnson, 2002), the volume of fluid pushed down on the $20 \mathrm{ml}$ syringes (left, L) side equals the volume of fluid that is lifted up on the $10 \mathrm{ml}$ syringes (right, R) side,

or,

$$
\mathrm{V}_{\mathrm{L}}=\mathrm{V}_{\mathrm{R}}
$$

when,

$$
A_{L} \times D_{L}=A_{R} \times D_{R}
$$

$\mathrm{A}=$ cross sectional area of syringes, $\mathrm{D}=$ the distance move of fluid

Figure 4 was shown that when pressing on $20 \mathrm{ml}$ syringes, resulting to the decreased fluid volume which related to the increased fluid volume of $10 \mathrm{ml}$ syringes. Meanwhile, pulling process on $20 \mathrm{ml}$ syringes, fluid volume increased which related to fluid volume decreased in $10 \mathrm{ml}$ syringes. These results were in accordance with the Pascal's law (Johnson, 2002).

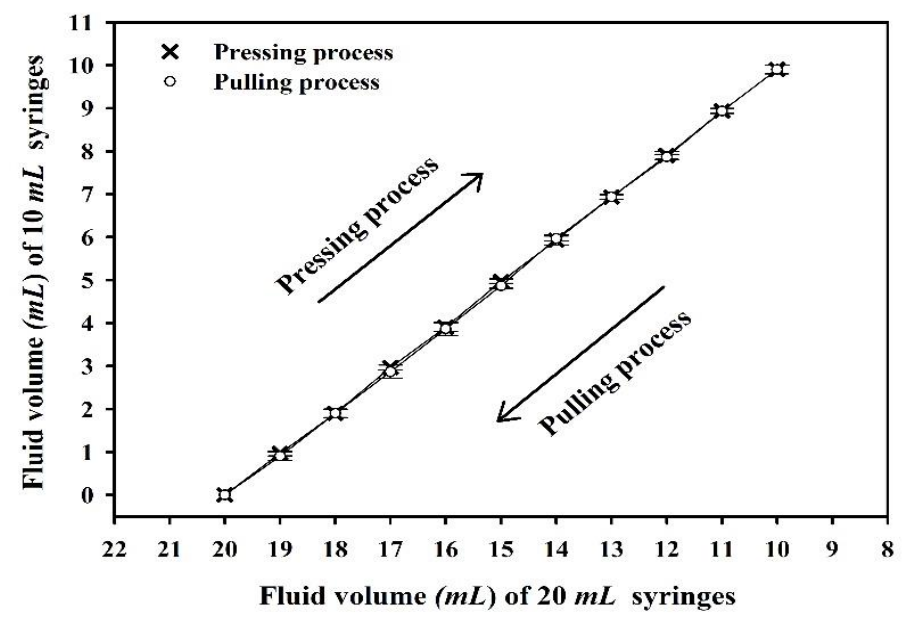

Figure 4. The pressing and pulling process effect of fluid volume in $20 \mathrm{ml}$ syringes (control) on fluid volume in $10 \mathrm{ml}$ syringes (fixed)

Therefore, the results obtained from the study of the fluid volume effect on syringes was applied to create learning media, in which students can build robotic from the above experiment. 
The robotic model for learning media consists of many parts such as arm segments, body segment, head segment, and leg segments. For the arm segments, there are base-arm joints, shoulder joints, elbow joints and hand joints. The pressing and pulling process effect of fluid volume in $20 \mathrm{ml}$ syringes (control) on movement mechanisms degree of robotic arm segments as presented in figure 5 and 6. Fluid volume of $20 \mathrm{ml}$ syringes decreased by pressing process affect on the increasing of movement mechanisms degree (base-arm joints, shoulder joints, elbow joints and hand joints) of robotic arm segments and joint angle of base-arm, shoulder, elbow and hand decreased with increasing of fluid volume of $20 \mathrm{ml}$ syringes via pulling process. Moreover, base-arm joint shown that the joint angle was lower than shoulder joints, elbow joints and hand joints, respectively. It may be due to the weight of each part of joint received from other parts, resulting in the resistance of the $10 \mathrm{ml}$ syringes rod movement and related to joint angle movement.

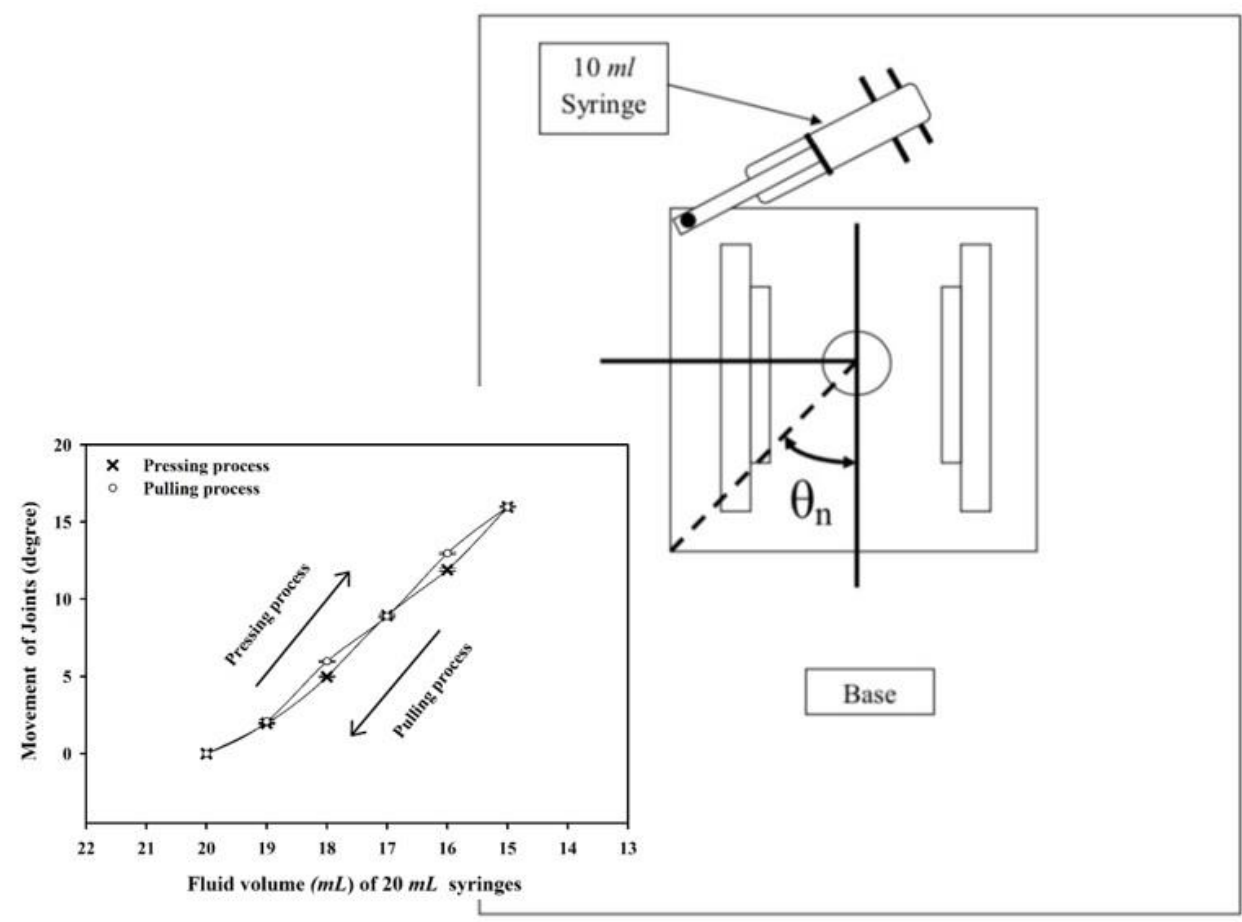

Figure 5. The pressing and pulling process effect of fluid volume in $20 \mathrm{ml}$ syringes (control) on movement mechanisms degree (joint angle: base-arm joint, $\left.\theta_{\mathrm{n}}\right)$ of base robotic arm segments 


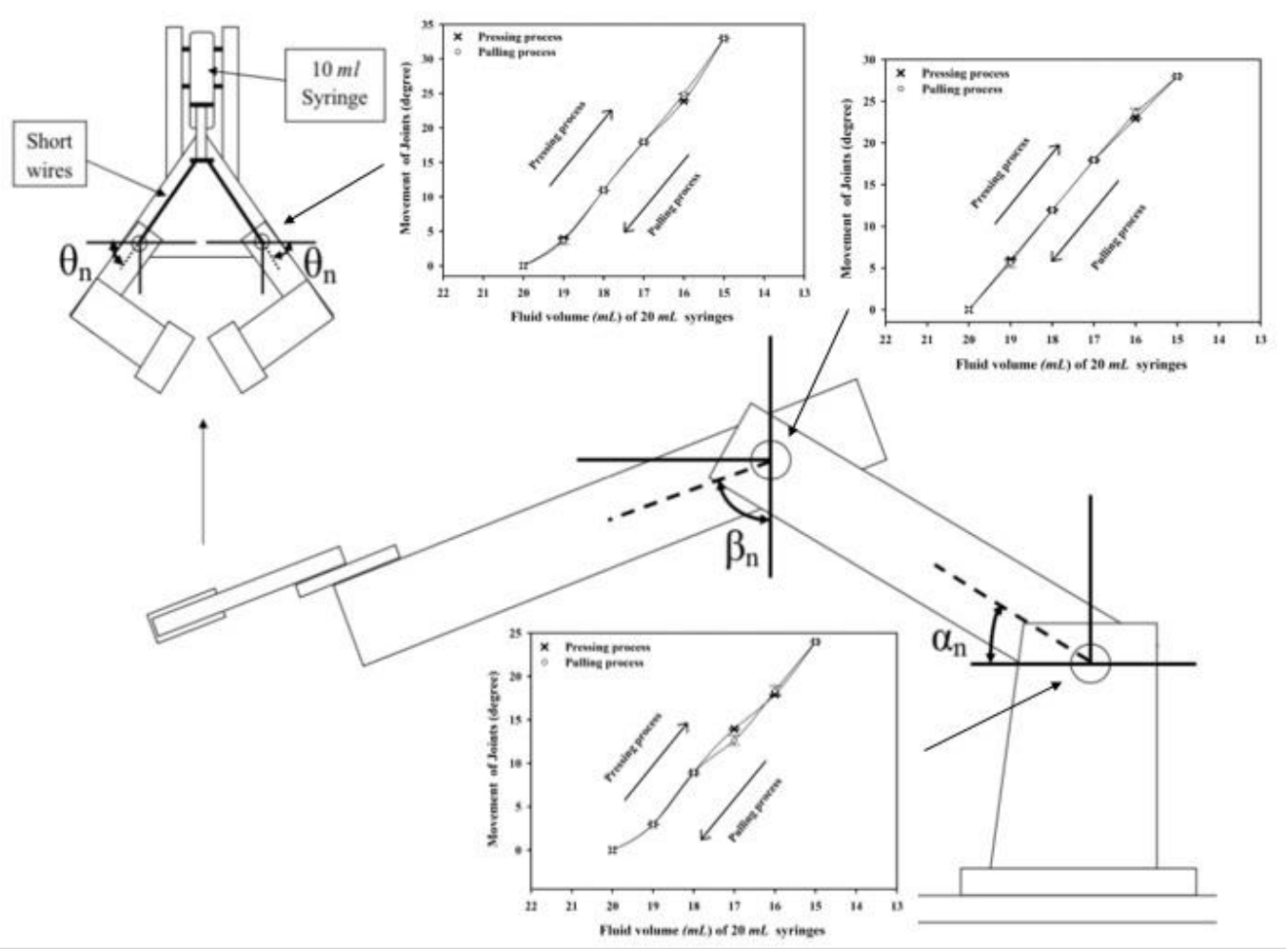

Figure 6. The pressing and pulling process effect of fluid volume in $20 \mathrm{ml}$ syringes (control) on movement mechanisms degree of robotic arm segments (joint angle: shoulder joints, $\alpha_{\mathrm{n}}$ : elbow joints, $\beta_{\mathrm{n}}$ : hand joints, $\theta_{\mathrm{n}}$ )

In term of robotic leg segments, it consists of ankle joints, knee joints and thigh joints as shown in figure 7. The effect of fluid volume in $20 \mathrm{ml}$ syringes via pressing and pulling process on movement mechanisms degree of robotic leg segments presented in figure 7 . The joint angle movement of robotic leg segment increased with decreasing of fluid volume in $20 \mathrm{ml}$ syringes when pressing. The pulling process on $20 \mathrm{ml}$ syringes as increased fluid volume, resulting to the joint angle movement decreased. In addition, due to each part weight of joint received from other parts affects the resistance of the $10 \mathrm{ml}$ syringes rod movement and related to joint angle movement. Therefore, ankle joints $\left(\theta_{\mathrm{n}}\right)$ shown the lower of joint angle movement compared to knee joints $\left(\alpha_{\mathrm{n}}\right)$ and thigh joints $\left(\beta_{\mathrm{n}}\right)$, respectively. 


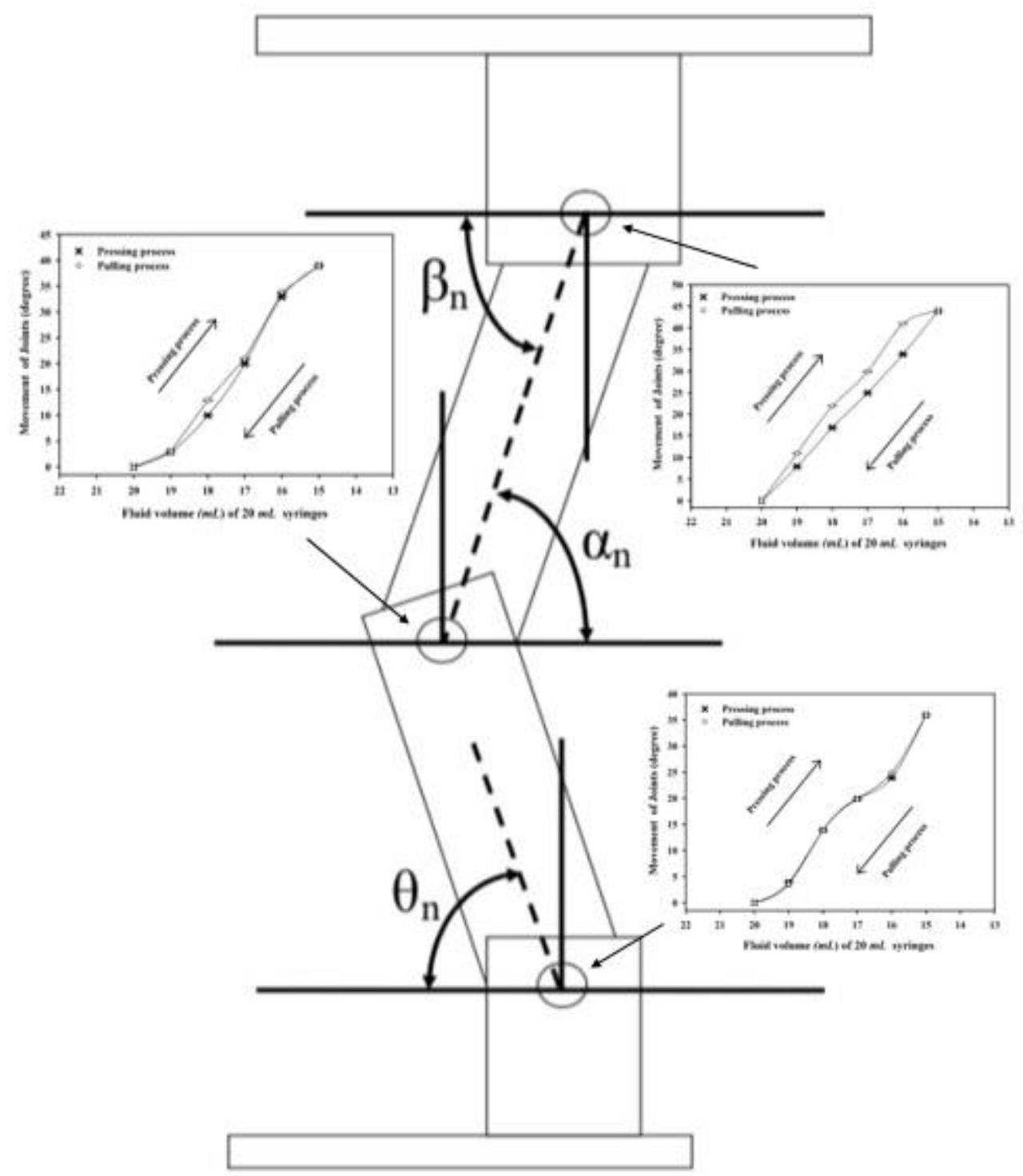

Figure 7. The pressing and pulling process effect of fluid volume in $20 \mathrm{ml}$ syringes (control) on movement mechanisms degree (joint angle: ankle joints, $\theta_{\mathrm{n}}$ : knee joints, $\alpha_{n}$ : thigh joints, $\beta_{n}$ ) of robotic leg segments

Moreover, the results of this study still followed Pascal's law (Johnson, 2002). Thus, after the students studied and analyzed the effect of fluid volume on movement joint mechanisms degree and understand the basic of Pascal's law to each joint. We know students understand the Pascal's law by observed their robot. The students who understand Pascal's law can successfully build robot that can move. They can build a reuse material robot by themselves as shown in figure 8 . Therefore, this leaning media is an important development leaning skill of students about the Pascal's law in physics. 

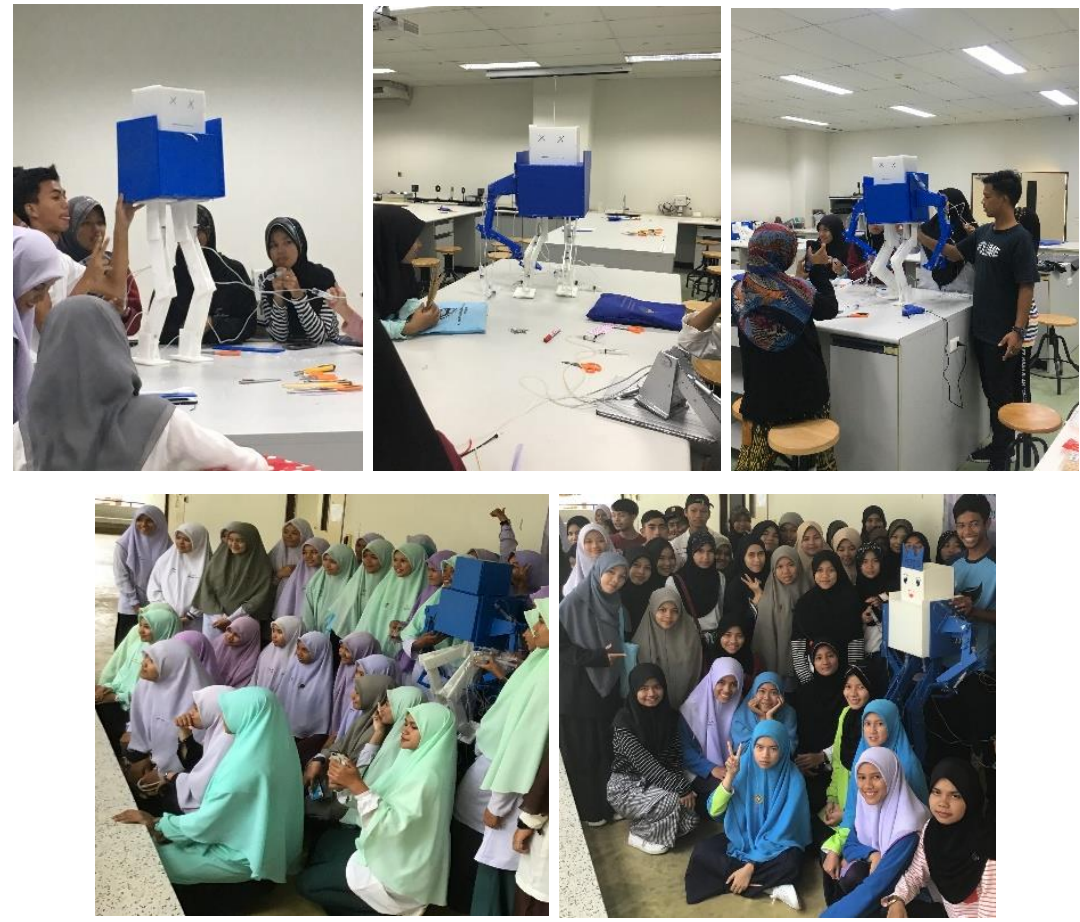

Figure 8. Students can participate in activities to create robotic leaning media

\section{Conclusion}

The effect of fluid volume on movement mechanisms degree of robotic learning media was found that the $20 \mathrm{ml}$ syringes via pressing and pulling process, resulting to the fluid volume of $10 \mathrm{ml}$ syringes and related to the movement mechanisms degree (joint angle) of robotic learning media. The interesting point of this study is that students can build a robot and learn basic Pascal's law in the same activities.

\section{References}

Johnson, J (2002). Introduction to fluid power. USA: Delmar Thomson Learning.

Bahaa, I. K., Ali, I. M., \& Ali, T. O. (2008). Motion planning for a robot arm by using genetic algorithm. Jordan journal of mechanical and industrial engineering, 2, 131-136.

Anisur, R., Alimul, H. K., Tofayel, A., \& Mohsin, S. (2013). Design, analysis and implementation of a robotic arm- the animator. American journal of engineering research, 2, 298-307.

Surendernath, P., \& Nagarajarao, K. (2015). Modelling of a robatic arm using solid works. International journal of research in advanced engineering technologies, 4, 347-364.

Jônatas, V. T., \& Marcelo da, S. H. (2015). Educational robotic simulators: a systematic literature review. Nuevas ideas en informática educativa TISE. 
Redmond, R. S., Cornelia, W., Ibrahim, A. H., Ian, J. Y., Tony, E. G., Siva, K. B., Lenka, P., Desa, A., \& Girish, C. (2018). Research and development in agricultural robotics: a perspective of digital farming. International Journal of Agricultural and Biological Engineering, 11(4), 1-14.

Kurt, E. C., \& Ying, S. (2010). A geometric approach for robotic arm kinematics with hardware design, electrical design, and implementation. Journal of robotics, (2010), 1-10.

Bin, F., Fuchun, S., Huaping, L., Di, G., Wendan, C., \& Guodong, Y. (2017). Robotic teleoperation systems using a wearable multimodal fusion device. International journal of advanced robotic systems, 14(4), 1-11.

Ross, M. M., Thomas, W. B., \& Adam, A. S. (2017). Integrating soft robotics with the robot operating system: a hybrid pick and place arm. Frontiers in robotics and AI, 4, 1-6.

Ashraf, E., Eduardo, Y., Karen, B., \& Ricardo, S. (2011). Design and development of a competitive low-cost robot arm with four degrees of freedom. Modern mechanical engineering, 1, 47-55.

Alka, N. U., Salihu, A. A., Haruna, Y. S., \& Dalyop, I. A. (2017). A voice controlled pick and place robotic arm vehicle using android application. American journal of engineering research, 6(7), 207-215.

Jiaqi, X., \& Hwan-Sik, Y. (2016). A review on mechanical and hydraulic system modeling of excavator manipulator system. Journal of construction engineering, 6, 1-11.

Abhinav, D. K., Akshay, S. K., Ajinkya, A. K., \& Bathe, A. T. (2019). Introduction to pneumatic robotic arm. International journal of research in engineering, science and management, 2(1), 688-691.

Hitoshi, K., Mokutaro, K., Shotaro, S., Daisuke, A., \& Norio, I. (2012). A flexible robotic arm with hydraulic skeleton. Journal of advanced mechanical design, systems, and manufacturing, 6(7), 1107-1120.

Stevenson, D. A., \& Lippay, A. L. (1986). Hydraulic powered arm systems. Proceedings of the Institution of Mechanical Engineering, 183, 37-44.

Faiyaz, A., Manash, D., Ashutosh, S., \& Dhruv, K. (2018). Hydraulic-powered robotic arm. International research journal of engineering and technology, 5(4), 4244-4247.

How to cite this article:

Taksapattanakul, K., Puteh, A., Arun, A., \& Saengwiman, S. (2020). The Pascal's Law of Physics Applied to Build a Reuse Material Robotic as Effective Physics Leaning Media. Journal of Educational Sciences, 4(2), 449458. 